\title{
Vertical structure and temporal evolution of an anticyclonic eddy in the Balearic Sea (western Mediterranean)
}

\author{
Angel Amores, ${ }^{1}$ Sebastià Monserrat, ${ }^{1,2}$ and Marta Marcos ${ }^{1}$ \\ Received 15 October 2012; revised 25 February 2013; accepted 26 February 2013; published 26 April 2013.
}

[1] An anticyclonic eddy in the Balearic Sea (western Mediterranean) was described using data from a mooring line deployed at the northern slope of Mallorca Island at about $900 \mathrm{~m}$ deep. Its surface signature was investigated using sea surface height and sea surface temperature images. The eddy, which lasted around 1 month, modified the thermohaline characteristics and the currents of the entire water column. Levantine Intermediate Waters, usually resident in the region, were displaced by colder and fresher Western Mediterranean Intermediate Waters associated with the eddy. Along-slope main currents (toward NE) were completely reversed at $500 \mathrm{~m}$ and significantly deviated at $900 \mathrm{~m}$.

Interestingly, near-bottom velocities were found to be systematically larger than those at intermediate depths. Furthermore, during the eddy, velocities reached values up to $26 \mathrm{~cm} / \mathrm{s}$ at the bottom, 5 times larger than the bottom average speed. The recurrence of the phenomenon was explored with an eddy detection tool applied to satellite observations. Results indicated that anticyclonic eddies are common structures in the Balearic Current.

Citation: Amores, A., S. Monserrat, and M. Marcos (2013), Vertical structure and temporal evolution of an anticyclonic eddy in the Balearic Sea (western Mediterranean), J. Geophys. Res. Oceans. 118, 2097-2106, doi:10.1002/jgrc.20150.

\section{Introduction}

[2] The Balearic Sea, located in the western Mediterranean, is the subbasin confined between the Iberian Peninsula and the Balearic Islands, covering the area from $38^{\circ} 45^{\prime} \mathrm{N}$ to $42^{\circ} 30^{\prime} \mathrm{N}$ and $0^{\circ} 20^{\prime} \mathrm{W}$ to $4^{\circ} 00^{\prime} \mathrm{E}$ (Figure 1 ). On the continental side, the shelf is relatively narrow $(15-30 \mathrm{~km})$, with the exception of the Ebro River delta southward, where it becomes wider up to $60-70 \mathrm{~km}$. The slope is very steep, with depth increasing from $200 \mathrm{~m}$ to over $1000 \mathrm{~m}$ in only a few kilometers. On the islands side, the shelf is even narrower $(5-20 \mathrm{~km})$, and the slope becomes steeper and discontinuous due to the channels between the islands. Between Cape La Nao (Iberian Peninsula) and Ibiza Island, there is the so-called Ibiza Channel with $80 \mathrm{~km}$ width and a maximum depth of $800 \mathrm{~m}$. The Mallorca Channel is located between Ibiza and Mallorca Islands, with approximately $80 \mathrm{~km}$ width and a maximum depth of $600 \mathrm{~m}$. The Menorca Channel is placed between Mallorca and Menorca Islands, and it is the narrowest (35 km width) and shallowest (100 m depth). Further details about the topographic characteristics of the region can be found, for example, in García et al. [1994].

[3] The oceanic mean circulation in the Balearic subbasin is generally cyclonic. Along the continental slope, the Catalan

\footnotetext{
${ }^{1}$ Mediterranean Institute for Advanced Studies (IMEDEA), CSIC-UIB, Mallorca, Spain. Spain.

${ }^{2}$ Departament de Física, Universitat de les Illes Balears (UIB), Mallorca,

Corresponding author: A. Amores, Mediterranean Institute for Advanced Studies (IMEDEA), CSIC-UIB, C/ Miquel Marquès, 21,ES-07190 Esporles, Mallorca, Spain. (aamores@imedea.uib-csic.es)

C2013. American Geophysical Union. All Rights Reserved. 2169-9275/13/10.1002/jgrc. 20150
}

Front [Font et al., 1988; La Violette et al., 1990] separates the fresher waters near the coast from saltier waters in the deeper basin. Its associated current, known as Northern Current (NC), flows southward along the continental slope and transports Atlantic Water from the Gulf of Lions toward the Balearic Channels (Figure 1). A bimodal behavior has been identified for the $\mathrm{NC}$ when it reaches the channels. In a normal situation, when the NC reaches the Ibiza Channel, it splits into two different branches. One branch flows through the channel, leaving the Balearic subbasin toward the Algerian subbasin. The other branch is cyclonically reflected and flows northward along the Balearic slope, forming the so-called Balearic Current (BC) with its associated Balearic Front (Figure 1). Simultaneously, other secondary currents flow northward into the Balearic subbasin from the Algerian subbasin through the channels. These currents transport fresher and warmer waters which join the BC. However, some of the inflow through the Ibiza Channel may be anticyclonically recirculated to the Algerian subbasin via the Mallorca Channel [Pinot et al., 2002].

[4] After winters colder than the average, the NC changes its usual path when it reaches the Ibiza Channel. Western Mediterranean Intermediate Waters (WIW) are formed in the Gulf of Lions during the winter season [Mertens and Schott, 1998; Millot, 1999; Pinot et al., 2002]. During cold winters, an additional amount of WIW, normally located between 100 and $300 \mathrm{~m}$, are formed, reaching the Balearic Channels later in spring [Pinot et al., 2002]. When this occurs, the branch which flows toward the Algerian subbasin may be blocked by the presence of mesoscale structures in the Ibiza Channel, so that the Balearic Current is then reinforced. The hydrodynamic characteristics of the subbasins and channels are strongly influenced then by the presence of WIW, which is basically controlled by the atmospheric conditions in the 


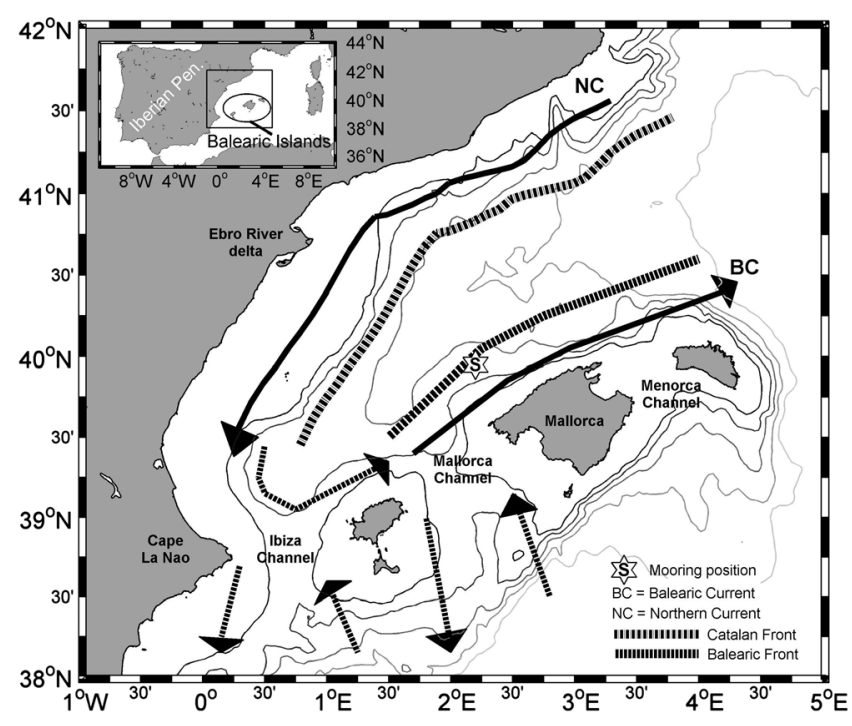

Figure 1. Map of the characteristics of the ocean circulation in the Balearic subbasin. The position of the mooring is marked with an $\mathrm{S}$ inside a star. Isobaths are plotted between 500 and $2500 \mathrm{~m}$ with a step of $500 \mathrm{~m}$. Solid arrows indicate permanent currents, while dashed arrows are temporal features.

northwestern Mediterranean during winter. Monserrat et al. [2008] defined a climatic index (the IDEA index), based on near-surface air temperature at the Gulf of Lions during winter months (from December to March), capable of successfully predicting the presence of WIW at the channels the following spring.

[5] The importance of the mesoscale variability of the Balearic Front has been largely underestimated because this front was thought to be more stable than the Catalan Front [La Violette et al., 1990]. This general point of view changed when López-García et al. [1994] observed significant mesoscale activity at the Balearic Front, with a large number of eddies and filaments. They concluded that the Balearic Front is the northward extension of the eddy-dominated regime of the Algerian subbasin, which is well known for its strong mesoscale activity [Millot et al., 1997]. Many works have shown afterward the existence of these structures in the Balearic Current using satellite data, drifting buoys, oceanographic cruises, gliders, and/or modeling tools [Tintoré et al., 1990; Pinot et al., 1994; Álvarez et al., 1996; Ruiz et al., 2009; Rubio et al., 2009; Balbin et al., 2012; Bouffard et al., 2012]. In particular, Pascual et al. [2002] described, with satellite and in situ data, the origin, development, and decay of an intense anticyclonic eddy which survived during 6 months, moving into the Balearic Sea and even producing a reversal of the cyclonic circulation of the subbasin. Balbin et al. [2012] used conductivitytemperature-depth (CTD) measurements, satellite data, and mooring data to study a front present at the north of Mallorca Island in December 2009. This structure evolved into an eddy which was later on measured by the mooring presented in this work. Most of the mesoscale structures in the region have been identified and described using the time evolution of surface data or by a 3-D spatial snapshot obtained from cruise hydrographic data. However, very scarce information exists so far on the temporal evolution of mesoscale structures for deeper levels.

[6] Mesoscale eddies are common structures in the ocean. They may have a topographic origin, when a bottom flow encounters a seamount, or atmospheric, when wind-driven currents, convergent or divergent, may result in the formation of such structures. Another well-known eddy formation mechanism consists of the intensification of an ocean current, which can lead to the development of a meander. Such meander may finally pinch off relatively warm or cool waters acting as the seed of an eddy. These eddies are sometimes referred to as rings.

[7] In this work, we describe the formation, development, and disappearance, as well as the hydrodynamic characteristics, of a mesoscale anticyclonic eddy recorded by a mooring line placed at the north of Mallorca Island, in the path of the Balearic Current. The eddy lasted in the region around 1 month, between November and December 2010. This is the first time that it has been possible to describe the complete temporal evolution for deeper levels of a mesoscale eddy in the Balearic Sea.

[8] This study is organized as follows: First, the data set and methodology are presented in section 2. In section 3, the hydrodynamic conditions of the eddy are shown, describing the surface situation and its vertical structure. Finally, in section 4 , the conclusions are presented.

\section{Data Sets and Methodology}

[9] Two different data sets were used in this study. The vertical structure was determined by means of observations from a mooring line, while the horizontal surface characteristics were studied using satellite data.

[10] The mooring line was deployed north of Mallorca Island $\left(39^{\circ} 49.682^{\prime} \mathrm{N}-2^{\circ} 12.778^{\prime} \mathrm{E}\right)$ from November 2009 until February 2011. It was placed at $900 \mathrm{~m}$ depth in the Mallorca's slope of the Balearic subbasin. The line consisted of four CTD Seabird 37 (at 300, 500, 700, and $900 \mathrm{~m}$ deep), two current meters Nortek Aquadopp (at 500 and $900 \mathrm{~m}$ deep), and a sediment trap at the bottom. Observations of thermohaline properties and currents were collected at sampling rates of $10 \mathrm{~min}$ for the CTD and $30 \mathrm{~min}$ for the current meters. Two maintenance surveys were carried out during the deployment period in order to recover the data stored in the instruments and to change batteries in December 2009 and July 2010. All instruments operated correctly during the entire period, except for the 500 and $900 \mathrm{~m}$ CTDs, which ran out of batteries in mid-December 2010 and mid-January 2011, respectively.

[11] Current meter observations were analyzed using wavelets [Liu and Miller, 1996], a standard tool widely used for the analysis of nonstationary data sets, including oceanographic observations [Emery and Thomson, 1998]. The time series from 1 November 2010 to 31 January 2011 were used in order to visualize the most energetic frequency bands before, during, and after the development of the eddy.

[12] Daily gridded absolute dynamic topography fields with a map spacing of $1 / 8^{\circ} \times 1 / 8^{\circ}$ were obtained from the merged satellite Archiving, Validation, and Interpretation of Satellite Oceanographic data(AVISO) products available at www.aviso.oceanobs.com. The absolute dynamic topography is calculated as the sum of the sea level anomalies and the mean dynamic topography [Rio et al., 2007]. The regional 
sea level anomalies for the Mediterranean Sea available at the AVISO server are a multimission product with up to four satellites at a given time, spanning the period from 1992 to present. All standard geophysical corrections were applied, including the so-called Dynamic Atmospheric Correction, produced by CLS. This correction combines the high frequency (H-F) of the Mog2D model [Carrère and Lyard, 2003] and the low frequency of the classical inverted barometer correction. These model outputs were used to correct the newly released altimeter data sets, therefore reducing the aliasing effects of H-F signals [Volkov et al., 2007]. The regional mean dynamic topography covers the Mediterranean Sea, and it is based on 7 years of observations (1993-1999). Despite its good performance in the open ocean and the wide range of applications, the altimetric products, both gridded and along track, fail when approaching the coast, mostly due to the land contamination in the signal. Several efforts are currently devoted to the recovery and improvement of near-coastal altimetry observations. However, this new generation of observations is not fully developed for the global coastal ocean yet, not even for the Mediterranean Sea.

[13] Daily sea surface temperature (SST) data were collected from MyOcean database (http://www.myocean.eu). The regional gridded product for the Mediterranean Sea is a high-resolution SST anomaly, computed using the CNR MED analysis at $1 / 16^{\circ} \times 1 / 16^{\circ}$ horizontal resolution and starting in December 2010.

[14] The time evolution of the eddy features was explored using the vector geometry-based eddy detection algorithm [Nencioli et al., 2010]. This scheme is a flow geometry-based method. The center of the eddy is determined by a local velocity minimum into an area where rotating flow has been detected. The eddy boundaries are defined as the outermost closed streamline around the center, across which velocity is still radially increasing.

[15] In order to improve the algorithm performance, the AVISO velocity fields were linearly interpolated from a $1 / 8^{\circ} \times 1 / 8^{\circ}$ grid to a $1 / 16^{\circ} \times 1 / 16^{\circ}$ grid, as it was performed in Liu et al. [2012]. Finally, the method was applied to the resultant fields with parameters $a=3$ and $b=2$. Parameter $a$ defines the amount of grid points away from a given point, in which the increases in magnitude of the velocity component $v$ along the EW axes and velocity component $u$ along the NS axes are checked, and $b$ is the dimension in grid points of the area used to define the velocity local minimum.

[16] Once the boundaries and the center of the eddy were established, its main features could be derived. The equivalent radius was calculated as the radius of a circumference with the same area than the area of the eddy; the circulation was the sum of the vorticity in all points inside the eddy area; and the SSH maximum was the maximum value of the SSH inside the limits of the eddy.

\section{Results and Discussion}

[17] During the operational time of the mooring, several mesoscale structures were identified in the Balearic Sea using satellite images. In the present work, we concentrated on an anticyclonic eddy observed between mid-November and mid-December 2010. Among all structures observed, this eddy generated the largest variations of the hydrodynamic characteristics of the intermediate and deep waters. In the following, the eddy is described from surface remote sensing observations and from moored in situ data.

\subsection{Surface Description of the Eddy}

[18] Figure 2 shows the temporal evolution of sea surface height (SSH) before, during, and after the eddy formation provided by the altimetry data. Prior to the eddy formation, SSH depicted the usual nonperturbed situation with the NC flowing southward along the mainland coast and the $\mathrm{BC}$ flowing northward along the islands' slope (BC) (Figure 2a). However, a small meander is observed in the Balearic Current starting to develop in front of the Mallorca Channel (Figure $2 b$ ) and strengthening (Figure 2c). The first day on which the automatic eddy detection scheme [Nencioli et al., 2010] detected the eddy (not shown) that remained almost stationary in the zone was on 21 November. Figures $2 d-2 j$ show the eddy boundaries of the fully developed anticyclonic structure which was detected with the method during 19 days. This anticyclonic structure partially blocked the surface circulation of the $\mathrm{NC}$ and forced the branch flowing along the shelf of the Islands to leave the Balearic subbasin through the Mallorca Channel.

[19] The evolution of the main features of the eddy is shown in Figure 3. The equivalent radius was confined between 4 and $28 \mathrm{~km}$ with an average value of $21.4 \mathrm{~km}$. Taking its mean radius and a mean velocity of $20 \mathrm{~cm} / \mathrm{s}$ at this point, the rotation period of the eddy rises around 8 days. The circulation varied between $-1.5 \times 10^{-4} \mathrm{~s}^{-1}$ and its minimum value $-6.8 \times 10^{-4} \mathrm{~s}^{-1}$, which coincided in time with the maximum SSH value $(18.4 \mathrm{~cm})$. The eddy was almost stationary (map in Figure 3), although, in the last part of its life, it shifted toward the mooring position.

[20] The last day in which the eddy was detected by the automatic scheme was on 10 December 2010. Nevertheless, a structure moving toward the mooring was still present in the subsequent images. Although the scheme did not detect the eddy, its existence cannot be ruled out due to the well-known troubles of satellite measurements near the coast. The structure weakened and disappeared (Figures $2 \mathrm{~m}-2 \mathrm{o}$ ), becoming first a meander of the current similar to Figure $2 b$.

[21] Changes in the sea surface temperature anomalies were also explored for the same period of time (Figure 4). Before the eddy formation (around 3 November 2010; not shown), the strongest feature was a very large SST gradient located between longitudes $2.75^{\circ} \mathrm{E}-6.50^{\circ} \mathrm{E}$ and latitudes $41^{\circ} \mathrm{N}-42^{\circ} \mathrm{N}\left(2.5^{\circ} \mathrm{C}\right.$ in around $\left.20 \mathrm{~km}\right)$. This gradient, found at the north of the Balearic Sea, was previously identified as the North Balearic Front [López-García et al., 1994; Millot, 1999]. The footprint of this gradient is still visible in Figure $4 \mathrm{a}$, with a negative temperature anomaly around $1.8^{\circ} \mathrm{C}$. At the same time, there was a core of warmer water growing southwest of the mooring position (Figures $4 \mathrm{a}-4 \mathrm{c}$ ) having as a result the formation of the eddy. The maximum temperature anomaly $\left(\sim 1^{\circ} \mathrm{C}\right)$ was observed on 28 November, with the eddy being fully developed. This region with warmer water surrounded by colder water disappeared in Figure $4 \mathrm{j}$ and subsequent images.

\subsection{Vertical Structure of the Eddy}

[22] The eddy development was recorded at different depths by the moored array of instruments. 

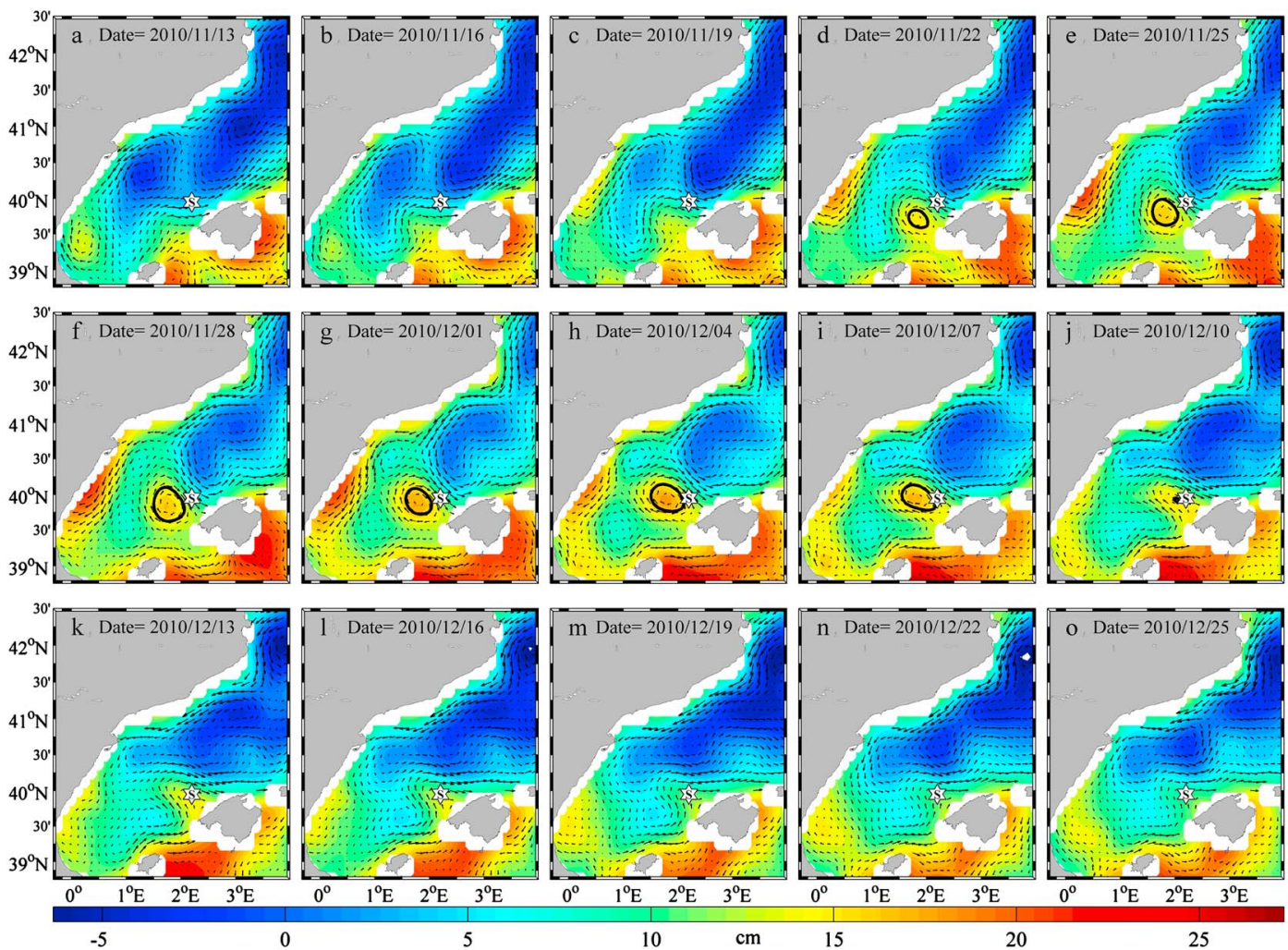

Figure 2. Sea surface height (SSH) images of the formation, development, and subsequent disappearance of the eddy. Colors indicate SSH (in $\mathrm{cm}$ ); vectors are the direction and modulus of the geostrophic currents associated to the SSH field; and the star with an S inside shows the mooring position. The dark enclosed area delimits the perimeter of the eddy following the criteria in Nencioli et al. [2010] (see text).

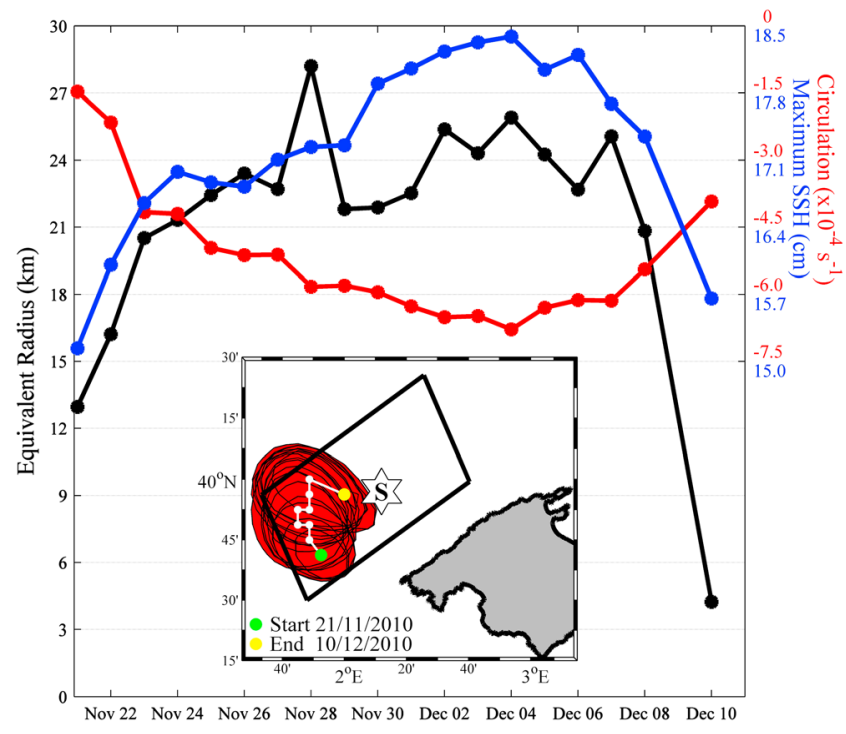

Figure 3. Main features of the eddy: the equivalent radius (black), the maximum SSH value (blue), and the circulation (red). In the inset map, the white line shows the trajectory of the eddy, and the red enclosed area shows the evolution of its surface location. The mooring position is marked with a star with an $\mathrm{S}$ inside. The thick black rectangle delimits the area used for the study of the recurrence of the phenomenon (see text for details).
[23] Figures $5 \mathrm{a}$ and $5 \mathrm{~b}$ show the progressive vector diagrams (PVDs) of the currents measured at 500 and $900 \mathrm{~m}$, respectively, between 10 November 2010 and 5 January 2011. The black part represents the normal situation for the currents in the zone: flowing northeastward along the slope (see Figure 1). Between 20 November and 19 December, a complete reversal of the current was measured at $500 \mathrm{~m}$ (grey part Figure 5a), which also had its footprint at $900 \mathrm{~m}$ (grey part Figure $5 \mathrm{~b}$ ). In the latter, the flow was not completely reversed but changed its direction in about $90^{\circ}$ becoming across slope.

[24] The current values for the same time period and depths are shown in Figure 6, decomposed in along-slope (Figures 6a and 6c) and across-slope (Figures 6b and 6d) components. Low-pass-filtered time series (with a cutoff frequency of $48 \mathrm{~h}$ ) are also plotted in red. The currents reached their maximum velocities during the episode. The mean current speed during the episode doubled the mean velocity values (from 2 to $4 \mathrm{~cm} / \mathrm{s}$ at $500 \mathrm{~m}$ and from 3 to $7 \mathrm{~cm} / \mathrm{s}$ at $900 \mathrm{~m}$ ) with maximum speeds of 19 and $26 \mathrm{~cm} / \mathrm{s}$ at 500 and $900 \mathrm{~m}$, respectively. It is worth mentioning that measured velocities, during the episode and in the normal situation, were constantly greater at $900 \mathrm{~m}$ depth than at $500 \mathrm{~m}$. The nonfiltered data also revealed that inertial oscillations of velocity were amplified during the episode.

[25] The changes in $T$ and $S$ associated to the presence of the eddy are plotted in Figure 7 , together with their low-pass-filtered time series. During the episode, a significant decrease of salinity $(0.35$, Figure $7 \mathrm{a})$ and temperature $\left(0.6^{\circ} \mathrm{C}\right.$, 

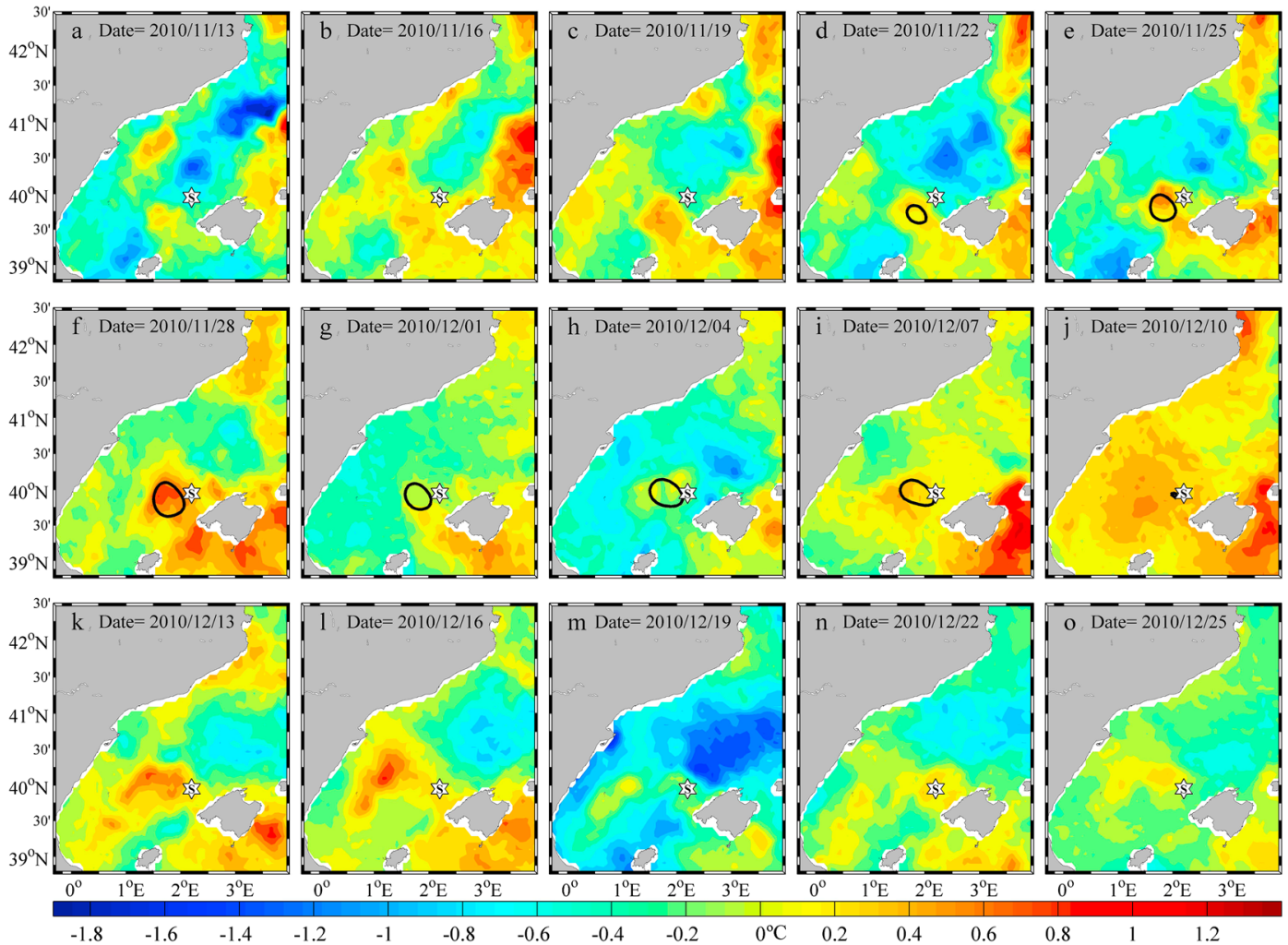

Figure 4. SST images of the same moments of the first four SSH images. Colors indicate the temperature of the sea surface; and the star with an S inside represents the mooring position. The dark enclosed area delimits the perimeter of the eddy following the criteria in Nencioli et al. [2010].

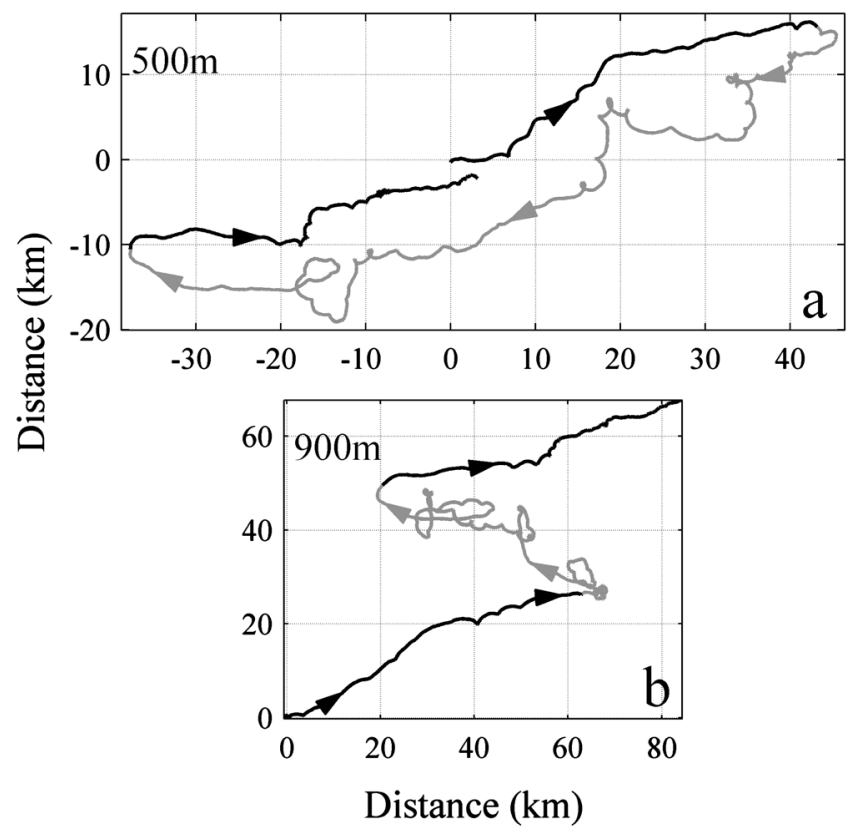

Figure 5. Progressive vector diagram (PVD) of the current meters at (a) $500 \mathrm{~m}$ and (b) $900 \mathrm{~m}$ depth from 10 November 2010 to 5 January 2011.

Figure $7 \mathrm{~b}$ ) at $300 \mathrm{~m}$ was observed. A reduction in salinity (at constant $T$ ) produces a reduction of density; likewise, a temperature drop (at constant $S$ ) is translated in an increase of density. Therefore, in terms of density, salinity reduction dominated over temperature cooling, thus decreasing density drastically at these levels (Figure 7e). At $700 \mathrm{~m}$, an increase of temperature and salinity was observed $\left(0.02\right.$ and $0.15^{\circ} \mathrm{C}$, respectively; Figures 7c and 7d). However, at this depth, salinity and temperature exchanged their roles, and temperature changes dominated and induced a decrease of density (Figure $7 \mathrm{~g}$ ). The combination of both effects guaranteed the stability of the water column. As for the velocity, it is noteworthy that inertial oscillations were amplified during the episode.

[26] The pressure record showed significant oscillations (Figures $7 \mathrm{f}$ and $7 \mathrm{~g}$ ) with decreasing magnitude in depth. The origin of these oscillations was not related to density changes or different heights of the water column since both variations tend to geostrophically compensate each other. Observed pressure changes were clearly linked to the increase of currents associated with the eddy, tilting the mooring up to $7^{\circ}$ and sinking the instruments below their usual depth. For the CTD deployed at $300 \mathrm{~m}$, the mooring tilt increased the pressure up to $4 \mathrm{dbar}$.

[27] Changes in water mass properties during the episode were explored through TS diagrams (Figure 8). At $300 \mathrm{~m}$, the drastic drop in temperature and salinity changed the properties of the resident water of the zone, Levantine Intermediate Water (LIW), to those of Western Mediterranean Intermediate Water (WIW), which is less saline, cooler, and lighter. This evidence suggests that the eddy at this depth was formed by WIW. These waters are generated in the Gulf of Lions during the winter season, transported by the NC 
AMORES ET AL.: DESCRIPTION OF AN EDDY (BALEARIC SEA)
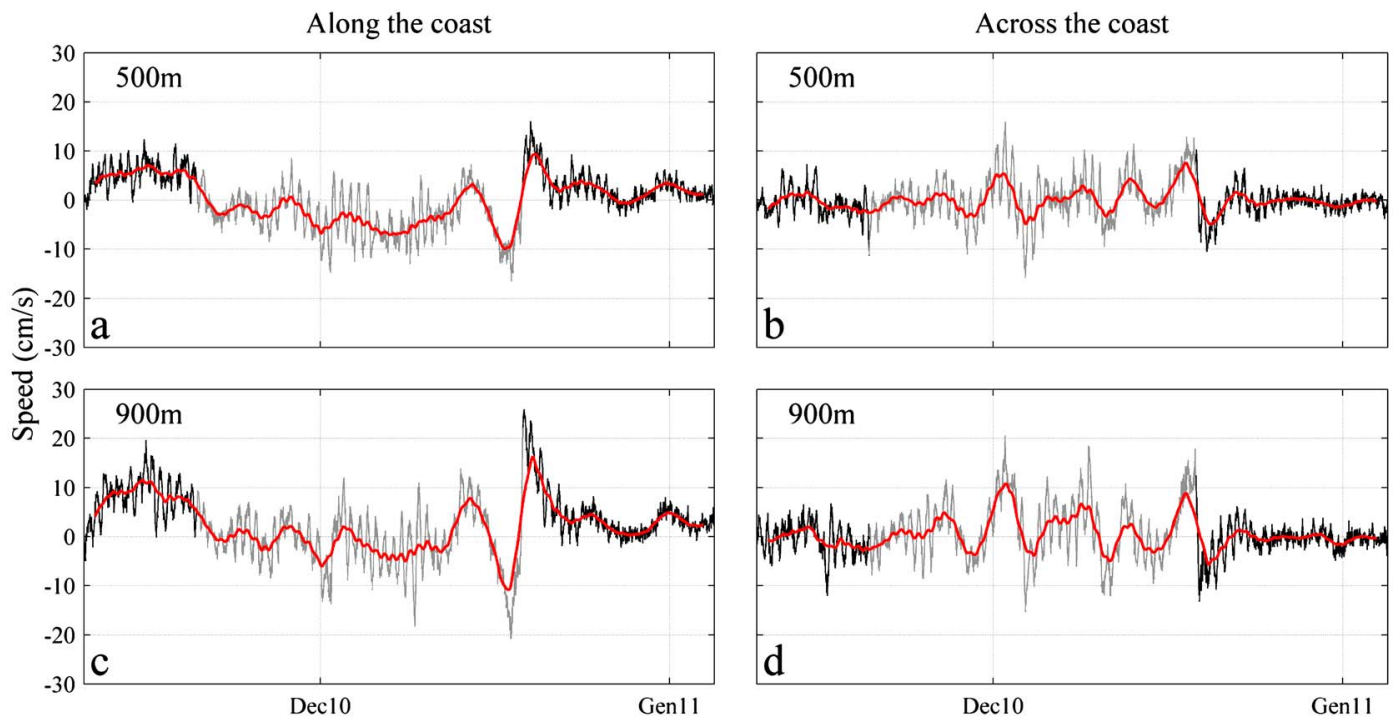

Figure 6. Currents measured in (a and b) $500 \mathrm{~m}$ and (c and d) $900 \mathrm{~m}$ decomposed along (see Figures 6a and $6 \mathrm{c}$ ) and across (see Figures $6 \mathrm{~b}$ and $6 \mathrm{~d}$ ) the coast components. The original record is presented in black and grey, and the 2 day low-pass-filtered series is presented in red.
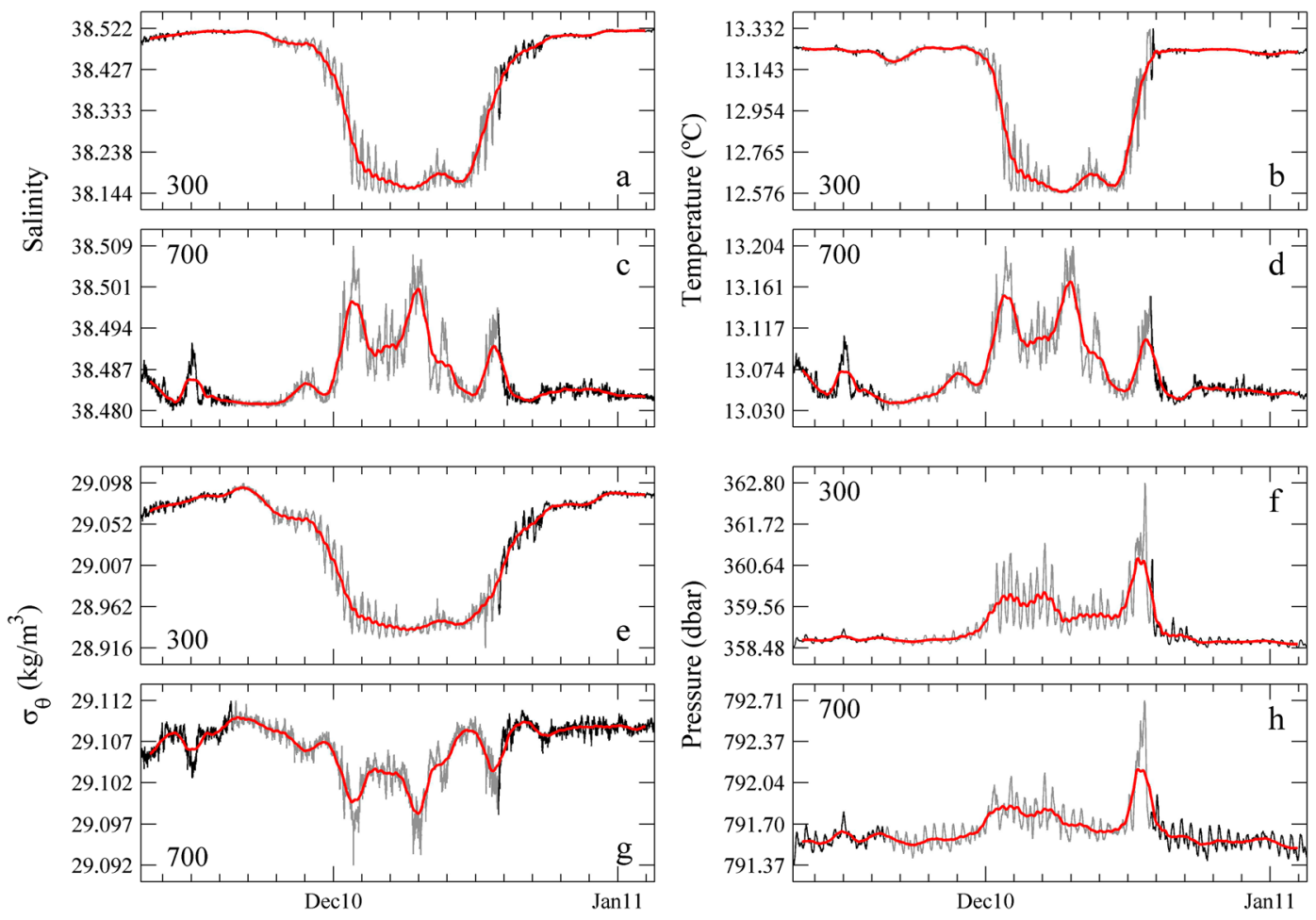

Figure 7. Time series of (a) salinity, (b) temperature, (c) potential density, and (d) pressure recorded by the Seabird37 at (1) $300 \mathrm{~m}$ and (2) $700 \mathrm{~m}$ from 10 November 2010 to 5 January 2011. The original record is presented in black and grey, and the 2 day low-pass-filtered series is presented in red.

southward reaching the Ibiza Channel typically in spring and may remain in the region until late autumn or early winter. Therefore, given the presence of WIW in the eddy at intermediate depths, it is hypothesized that the meander, and later the eddy formed in the $\mathrm{BC}$, transported WIW remaining in the Mallorca Channel to the mooring position. When the eddy disappeared, the water characteristics returned to LIW. At deeper levels (700 $\mathrm{m}$ in Figure 8), TS diagrams show how Western Mediterranean Deep Waters (WMDW) that usually occupy these levels were displaced by LIW during the episode.

[28] Figure 9 depicts the temporal changes in density throughout the water column and during the presence of the eddy, as recorded by the instrumental array of CTDs. The values in depths were interpolated using splines, whereas a 1 week running average was applied to the 


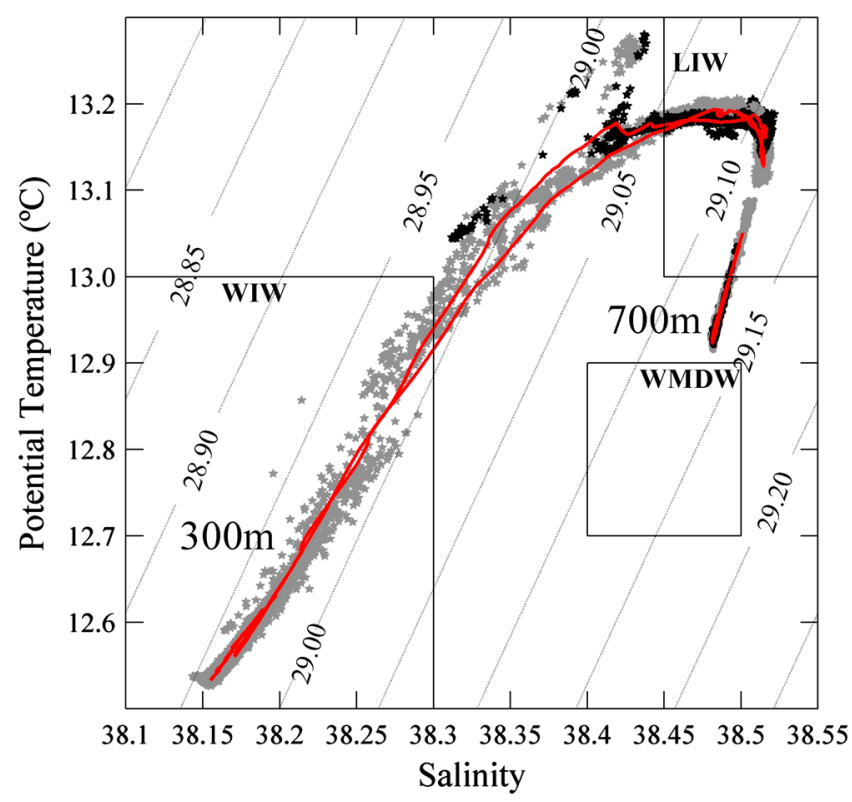

Figure 8. TS diagram of $300 \mathrm{~m}$ (series with stars) and $700 \mathrm{~m}$ (dotted series) recorded from 10 November 2010 to 5 January 2011. The original record is presented in black and grey, and the 2 day low-pass-filtered series is presented in red.

temporal time series in order to remove the high-frequency signals. Time series (without mean value) are also provided for comparison (note that vertical scales are proportional to the $300 \mathrm{~m}$ scale for the sake of comparison). The effects of the eddy were reflected in a deepening of the isopycnals and were substantial in the entire water column. In particular and compared with values at $300 \mathrm{~m}$, the effect in $500 \mathrm{~m}$ is around 3 times weaker; in $700 \mathrm{~m}$, it is 6-7 times smaller; and in $900 \mathrm{~m}$, it has been attenuated by more than 18 times.

[29] Changes in the frequency domain of the current records were explored using wavelets. The length of the time series used is 92 days (from 1 November to 31 January) with a sampling interval of $30 \mathrm{~min}$. As the eddy is anticyclonic, only the clockwise components of the currents were explored [Liu and Miller, 1996]. Highest energies were found at periods of a few days, associated with the rotation of the eddy itself and with synoptic-scale atmospheric forcing. However, anticyclonic eddies trap inertial waves, being their effective period inside the eddy larger than outside due to the sum of the relative vorticity of the eddy [e.g., D'Asaro, 1995]. Therefore, only periods between 1 and $50 \mathrm{~h}$ were explored. The clockwise wavelets of the currents at 500 and $900 \mathrm{~m}$ for such period bands are represented in Figure 10. Two thick vertical lines denote the time in which the reversal of the currents was detected. At both depths, higher energy levels were concentrated around the inertial frequency $f\left(\lambda=39.83^{\circ}, T_{f}=18.7 \mathrm{~h}\right.$, indicated in the plot as a horizontal line). This observation is in agreement with the fact that inertial oscillations appeared amplified in the velocity, temperature, and salinity time series (Figures 6 and 7). According to Figure 2, the eddy did not cross the mooring position, except tangentially at the end of its life. Therefore, the increase of energy at the inertial frequency corresponds to the detection of a meander circulating around the eddy periphery. However, around 19 December, there was a significant increase of the energy at periods between 30 and $40 \mathrm{~h}$, suggesting an inertial wave trapping caused by the eddy. The fact that the inertial energy increased in the clockwise wavelet and not in the counterclockwise (not shown) is in agreement with the anticyclonic character of the eddy.

[30] It is also noteworthy that the energy content was higher, clearer, and more constant at $900 \mathrm{~m}$ than at $500 \mathrm{~m}$ during the eddy life, which indicates once again that the eddy signal reached higher depths and that it had an important effect even near the bottom.

\subsection{Recurrence of the Phenomenon}

[31] It has been shown above that the presence of an anticyclonic eddy in the path of the $\mathrm{BC}$ can seriously distort the current regime in the Balearic Sea and have an impact on
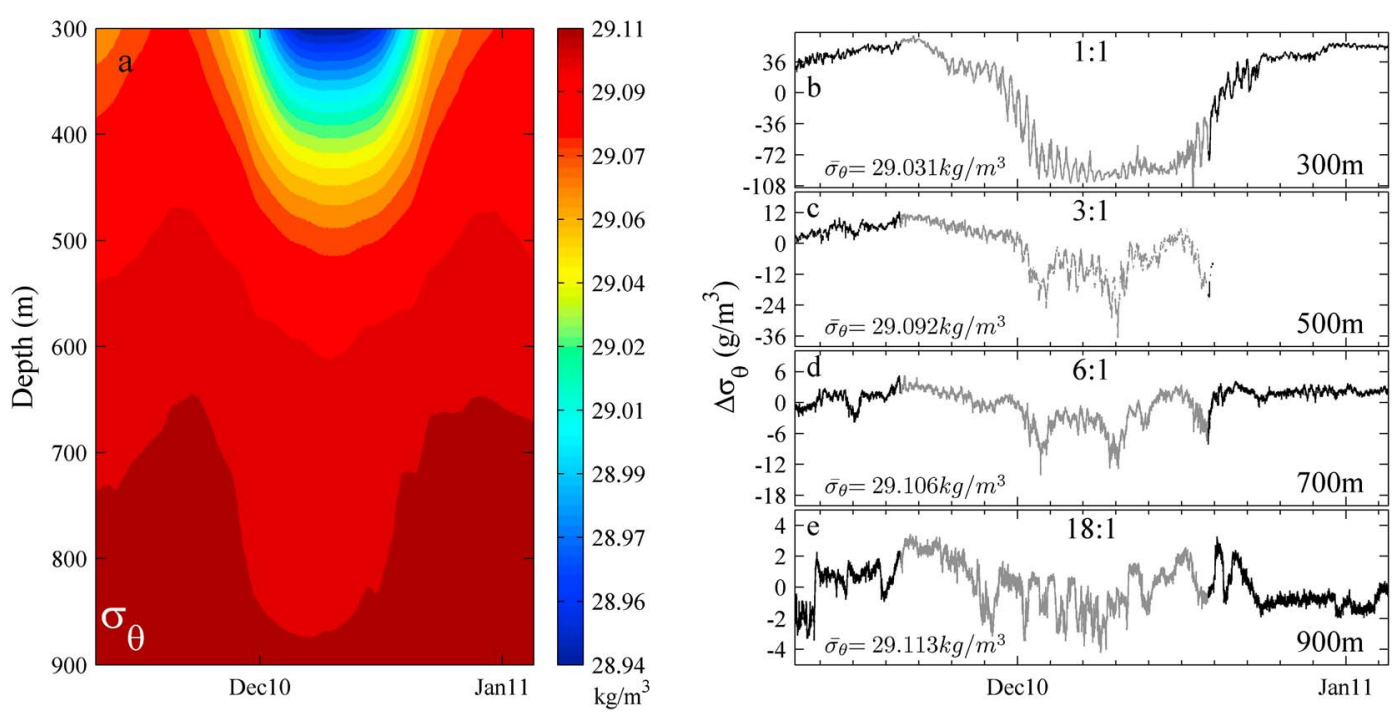

Figure 9. (a) Temporal evolution of the vertical structure of the density interpolating the values in depth using splines and density time series (without mean value) as measured for the moored instruments at (b) $300 \mathrm{~m}$, (c) $500 \mathrm{~m}$, (d) $700 \mathrm{~m}$, and (e) $900 \mathrm{~m}$. 

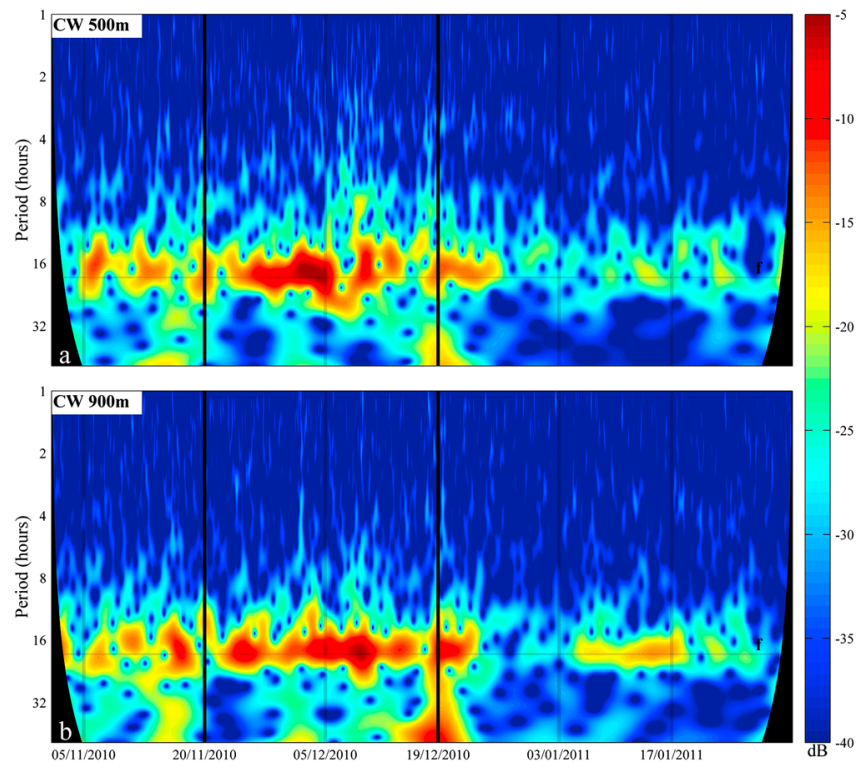

Figure 10. Clockwise wavelet of currents at (a) $500 \mathrm{~m}$ and (b) $900 \mathrm{~m} . f$ is the inertial frequency $(18.73 \mathrm{~h})$. Units are $\mathrm{dB}$.

the entire water column. Thus, the frequency at which these phenomena take place may have implications for the hydrodynamics of the area. With the aim of determining the repeatability of this episode, the automatic eddy detection tool from Nencioli et al. [2010] was used in the same region where the mooring was deployed (rectangle of $1^{\circ} \times 0.5^{\circ}$ in the map in Figure 3) for the period 1992-2011. The episodes were chosen to satisfy two criteria: first, the total time in which the eddy was detected by the method (referred to as duration hereinafter) must be at least 10 days, a value which corresponds to half of the duration of our target eddy; and second, the center of the eddy must remain at least 1 day inside the area. These criteria are subjective, and the final number of episodes would change if the area or the duration were modified. Our goal was not to perform a detailed statistical analysis but only to compare the studied eddy with a regular situation in the region affected by the Balearic Current.

[32] Table 1 lists the starting and ending dates, the duration (in days), the total circulation, the relative circulation compared with our eddy, and its mean radius of the 37 episodes that fulfill all the criteria, sorted by decreasing circulation. The circulation is calculated as the sum of the vorticity over the whole eddy area and for all days of its duration.

[33] The eddy of the longest duration took place in August 2008 with 66 days. The mean duration of the selected eddies was 21 days with a standard deviation of 12 days. The mean radius was $16 \mathrm{~km}$ with a standard deviation of $4.5 \mathrm{~km}$. Although most of the episodes (23) took place during

Table 1. List of Events That Fulfill the Selection Criteria From 1992 to 2011

\begin{tabular}{|c|c|c|c|c|c|c|}
\hline & Start & End & Duration (days) & Circulation $\left(10^{-3} \mathrm{~s}^{-1}\right)$ & Percentage (Circ/Circ Our) & Radius $(\mathrm{km})$ \\
\hline \multirow{7}{*}{$-\hat{s}$} & $13 / 03 / 1999$ & 14/04/1999 & 33 & -13.11 & 181.7 & 14.63 \\
\hline & 22/04/1999 & 04/05/1999 & 13 & -10.02 & 138.9 & 10.83 \\
\hline & $10 / 11 / 1995$ & $25 / 11 / 1995$ & 16 & -10.01 & 138.8 & 9.80 \\
\hline & $04 / 01 / 2009$ & $24 / 01 / 2009$ & 19 & -9.10 & 126.2 & 13.70 \\
\hline & $29 / 12 / 1995$ & 09/01/1996 & 12 & -7.38 & 102.3 & 8.69 \\
\hline & $21 / 11 / 2010$ & $10 / 12 / 2010$ & 19 & -7.21 & 100.0 & 21.40 \\
\hline & $05 / 12 / 2001$ & $29 / 12 / 2001$ & 25 & 7.17 & 99.4 & 21.90 \\
\hline & $15 / 07 / 2001$ & 03/08/2001 & 20 & 6.31 & 87.5 & 13.81 \\
\hline \multirow[t]{4}{*}{ घ } & $28 / 01 / 2010$ & $09 / 02 / 2010$ & 13 & -6.10 & 84.6 & 13.43 \\
\hline & $03 / 06 / 2001$ & $04 / 07 / 2001$ & 32 & 5.96 & 82.6 & 19.90 \\
\hline & $27 / 07 / 1998$ & $18 / 08 / 1998$ & 22 & 5.93 & 82.3 & 16.60 \\
\hline & $16 / 11 / 2008$ & $04 / 12 / 2008$ & 18 & 5.43 & 75.4 & 25.39 \\
\hline \multirow[t]{9}{*}{ घ } & $19 / 02 / 2010$ & $03 / 03 / 2010$ & 13 & -5.01 & 69.5 & 10.49 \\
\hline & $21 / 08 / 2007$ & $03 / 09 / 2007$ & 14 & 3.77 & 52.3 & 18.05 \\
\hline & $20 / 06 / 2009$ & 09/07/2009 & 20 & -3.72 & 51.6 & 15.01 \\
\hline & 09/07/1999 & 22/07/1999 & 13 & -3.57 & 49.5 & 15.79 \\
\hline & $05 / 08 / 2010$ & $16 / 08 / 2010$ & 12 & -3.46 & 47.9 & 14.84 \\
\hline & $30 / 05 / 2002$ & $15 / 06 / 2002$ & 17 & -3.45 & 47.9 & 17.06 \\
\hline & $27 / 05 / 2005$ & $06 / 06 / 2005$ & 11 & -2.81 & 39.0 & 21.81 \\
\hline & $26 / 05 / 1996$ & $11 / 06 / 1996$ & 17 & -2.66 & 36.9 & 10.59 \\
\hline & $20 / 08 / 2008$ & $26 / 10 / 2008$ & 66 & -2.44 & 33.9 & 18.88 \\
\hline \multirow[t]{16}{*}{$\bullet$} & $12 / 06 / 2010$ & $15 / 07 / 2010$ & 34 & -2.38 & 32.9 & 7.75 \\
\hline & $19 / 10 / 1998$ & $30 / 10 / 1998$ & 12 & 2.28 & 31.6 & 14.50 \\
\hline & $30 / 10 / 2008$ & $27 / 12 / 2008$ & 59 & 2.00 & 27.7 & 12.77 \\
\hline & 05/09/1994 & $01 / 10 / 1994$ & 27 & 1.68 & 23.3 & 13.26 \\
\hline & 03/08/1994 & $25 / 08 / 1994$ & 22 & 1.68 & 23.3 & 11.98 \\
\hline & 06/04/1993 & $15 / 04 / 1993$ & 10 & 1.50 & 20.8 & 11.89 \\
\hline & $01 / 04 / 1995$ & $17 / 04 / 1995$ & 17 & 1.45 & 20.1 & 16.84 \\
\hline & $23 / 04 / 2008$ & $13 / 05 / 2008$ & 19 & 1.40 & 19.4 & 12.28 \\
\hline & $12 / 06 / 2010$ & $02 / 07 / 2010$ & 18 & -1.39 & 19.3 & 20.22 \\
\hline & $29 / 04 / 2010$ & $06 / 06 / 2010$ & 39 & 1.29 & 17.9 & 22.16 \\
\hline & $07 / 03 / 2005$ & $16 / 03 / 2005$ & 10 & 0.75 & 10.4 & 16.04 \\
\hline & $04 / 11 / 2005$ & $16 / 11 / 2005$ & 13 & -0.58 & 8.0 & 23.41 \\
\hline & $07 / 01 / 2008$ & $23 / 01 / 2008$ & 17 & 0.43 & 6.0 & 21.69 \\
\hline & $08 / 05 / 2002$ & $20 / 05 / 2002$ & 12 & -0.36 & 5.0 & 21.63 \\
\hline & $09 / 07 / 1995$ & $22 / 07 / 1995$ & 14 & 0.30 & 4.1 & 18.06 \\
\hline & $21 / 07 / 2002$ & $13 / 08 / 2002$ & 24 & -0.12 & 1.6 & 17.35 \\
\hline
\end{tabular}


warmer months, from April to September, the most intense eddies in terms of circulation occurred in colder months (October-March). More precisely, 9 of the 13 most intense eddies occurred during winter time. This fact is related to the intensification of the Northern Current during the winter season, which also affects the Balearic Current [Pinot et al., 2002]. Moreover, 17 of the 22 most intensive eddies were anticyclonic.

[34] The eddy studied in this paper is the 6th most intense of all the eddies fulfilling the selection criteria (star with an S inside, see Table 1) and the 8th in terms of the length of the radius $(21.40 \mathrm{~km})$, although it is only the 16 th longest.

[35] During 2010, there were a total of three episodes similar to our eddy measured by the mooring. The first episode, described in Balbín et al. [2012], corresponds to the two eddies marked with a square in Table 1 . The second eddy is marked with a circle in Table 1 . The eddy described in this paper is the most intense measured by the mooring in terms of circulation and the only one which presents a clear footprint at the bottom and the largest changes in temperature and salinity.

\section{Summary and Conclusions}

[36] A mooring line deployed at the northern slope of Mallorca Island (western Mediterranean) during more than 1 year measured the effects of a strong anticyclonic eddy (the 6th with higher total circulation and the 8th with bigger radius) that modified the hydrodynamic properties in the whole water column $(\sim 1000 \mathrm{~m})$. The eddy remained in the area about 1 month (November-December 2010) and caused a complete reversal of the current direction at $500 \mathrm{~m}$ and a change of $90^{\circ}$ in $900 \mathrm{~m}$ with respect to the along-slope main direction under unperturbed conditions. CTD observations indicated that the core of the eddy was formed by Western Mediterranean Intermediate Waters (WIW) at depths between 300 and 700 m, while Levantine Intermediate Waters (LIW) were found at deeper levels $(700-900 \mathrm{~m})$. It is suggested, based on satellite altimetry observations, that the eddy was formed as a consequence of a meander in the Balearic Current which transported WIW northward from the Mallorca Channel. As WIW present lower temperatures and salinity than the resident LIW, its presence during the eddy episode was clearly detected through TS diagrams.

[37] It has been shown that the presence of the eddy affected the entire water column. This finding is in agreement with Pinot et al. [2002], who showed the presence of an eddy down to $500 \mathrm{~m}$, and contrasts with other reported mesoscale structures in the western Mediterranean which did not extend deeper than $300 \mathrm{~m}$ [Font et al., 1988; Pinot et al., 1994]. In our area of study, however, all eddies measured during the time in which the mooring was deployed have a clear footprint at $500 \mathrm{~m}$ and a weaker one at $900 \mathrm{~m}$ (not shown).

[38] Interestingly, the comparison of current meter and CTD measurements revealed a 10 day time lag between the beginning of the observed current reversal at $500 \mathrm{~m}$ and the later appearance of WIW. This lag is consistent with an eddy formed by a core of WIW generated west from the observation site and shifted toward the mooring position, as shown by SSH and SST images. In this case, currents associated with the external part of the eddy affect the area before the entrance of the core.
[39] The same time lag was also observed when the eddy disappeared. The currents returned to its usual direction before the hydrodynamic properties recovered their usual values. As also suggested by satellite images, this fact was a consequence of the extinction of the eddy over the observation area. The currents recovered their unperturbed direction, and the WIW core waters were then swept out of the area.

[40] Current meter observations revealed that velocities were higher at $900 \mathrm{~m}$ than at $500 \mathrm{~m}$ during the entire period of observation. In particular, averaged values of velocity were $4 \mathrm{~cm} / \mathrm{s}$ at $500 \mathrm{~m}$ and $7 \mathrm{~cm} / \mathrm{s}$ at $900 \mathrm{~m}$ and reached peak values up to $26 \mathrm{~cm} / \mathrm{s}$ at $900 \mathrm{~m}$. This effect is not new and was also reported in other places in the western Mediterranean [Millot, 1994], but it still remains unclear [Pinot et al., 2002]. Since velocities measured at the surface by altimetry were larger than at intermediate depths (and probably the near-surface velocities, too), it is suggested that the velocity reaches its minimum at some unknown intermediate depth. More current meter observations at additional depths would be needed to estimate the complete vertical velocity profile of the Balearic Current, paying special attention from surface up to $300 \mathrm{~m}$ where data were not acquired. The $90^{\circ}$ turn in the bottom currents at $900 \mathrm{~m}$, which caused a change in its main direction from along slope to cross slope, could be related to turbidity currents generated by the eddy resuspending sediments from the seabed. This turbid water would become heavier than the water below, and it would fall downslope. Previous studies suggested that a small amount of resuspended material could give rise to significant downslope velocities [Thomson et al., 2010]. This suggestion is supported by the fact that the total flux mass recorded by the sediment trap during the eddy life is around 2 times larger $\left(595 \mathrm{mg} \mathrm{m}^{2} \mathrm{~d}^{-1}\right)$ than its average for the entire deployment period $\left(313 \mathrm{mg} \mathrm{m}^{2} \mathrm{~d}^{-1}\right.$ ).

[41] A reference level of zero velocity at about $500 \mathrm{~m}$ has been usually taken in the computation of the dynamic height from hydrographic observations in the region of study. Our observations indicated that this approximation does not hold, as significant average velocities of $4 \mathrm{~cm} / \mathrm{s}$ at $500 \mathrm{~m}$ were found. It is advisable therefore to account for this effect in the computation of dynamic heights.

[42] Acknowledgments. This research was partially sponsored by the IDEADOS project (proyecto del Plan Nacional CMT2008-04489-C03-03). The work of A. A. was funded by a JAE-PreDoc grant from Consejo Superior de Investigaciones Científicas (CSIC) and cofunded by Programa Operativo FSE 2007-2013. M. M. acknowledges a "Ramon y Cajal" contract funded by the Spanish Ministry of Economy and Competitiveness. The authors are grateful to Richard Thomson, D. Gomis, G. Jordà, and M. Flexas for useful discussions on the paper. The authors are deeply grateful to all the IDEADOS team for their collaboration in the data acquisition process. We also wish to thank three anonymous reviewers for their valuable comments on the manuscript and N. Oliver for helping with the English. A. A. wants to thank Maiman Oliver for their invaluable help in the interpretation of the results found.

\section{References}

Álvarez, A., J. Tintoré, and A. Sabatés (1996), Flow modification and shelf-slope exchange induced by a submarine canyon off the northeast Spanish coast, J. Geophys. Res., 101, 12043-12055.

Balbín, R., M. M. Flexas, J. L. López-Jurado, M. Peña, A. Amores, and F. Alemany (2012), Vertical velocities and biological consequences at a front detected at the Balearic Sea, Cont. Shelf Res., 47, 28-41, doi:10.1016/j.csr.2012.06.008.

Bouffard, J., L. Renault, S. Ruiz, A. Pascual, C. Dufau, and J. Tintoré (2012), Sub-surface small-scale eddy dynamics from multi-sensor observations 


\section{AMORES ET AL.: DESCRIPTION OF AN EDDY (BALEARIC SEA)}

and modeling, Prog. Oceanogr., 106, 62-79, doi:10.1016/j.pocean. 2012.06.007.

Carrère, L., and F. Lyard (2003), Modelling the barotropic response of the global ocean to atmospheric wind and pressure forcing-Comparisons with observations, Geophys. Res. Lett., 30, doi:10.1029/2002GL016473.

D'Asaro, E. A. (1995), Upper-ocean inertial currents forced by a strong storm. Part III: Interaction of inertial currents and mesoscale eddies, J. Phys. Oceanogr., 25, 2953-2958.

Emery, W. J., and R. E. Thomson (1998), Data Analysis Methods in Physical Oceanography, pp. 500-509, Pergamon, Netherlands.

Font, J., J. Salat, and J. Tintoré (1988), Permanent features in the general circulation of the Catalan Sea, Oceanol. Acta, 9, 51-57.

García, E., J. Tintoré, J. M. Pinot, J. Font, and M. Manriquez (1994), Surface Circulation and Dynamics of the Balearic Sea, Coastal Estuarine Stud., 46, 73-91.

La Violette, P. E., J. Tintoré, and J. Font (1990), The surface circulation of the Balearic Sea, J. Geophys. Res., 95, 1559-1568.

Liu, P. C., and G. S. Miller (1996), Wavelet transforms and ocean current data analysis, J. Atmos. Oceanic Technol., 13, 1090-1099.

Liu, Y., C. Dong, Y. Guan, D. Chen, J. McWilliams, and F. Nencioli (2012), Eddy analysis in the subtropical zonal band of the North Pacific Ocean, Deep Sea Res., Part I, 68, 54-67, doi:10.1016/j.dsr.2012.06.001.

López-García, M. J., C. Millot, J. Font, and E. García-Ladona (1994), Surface circulation variability in the Balearic Basin, J. Geophys. Res., 99(C2), 3285-3296.

Mertens, C., and F. Schott (1998), Interannual variability of deep-water formation in the northwestern Mediterranean, J. Phys. Oceanogr., 28, 1410-1424

Millot, C. (1999), Circulation in the western Mediterranean Sea, J. Mar. Syst., 20, 423-442.

Millot, C. (1994), Models and data: A synergetic approach in the western Mediterranean Sea, in Ocean Processes in Climate Dynamics: Global and Mediterranean Examples, edited by P. Malanotte-Rizzoli and A. R. Robinson, pp. 407-425, Kluwer Acad., Dordrecht, Netherlands.

Millot, C., M. Benzohra, and I. Taupier-Letage (1997), Circulation off Algeria inferred from the Mediprod-5 current meters, Deep Sea Res., Part I, 44, 1467-1495.

Monserrat, S., J. L. López-Jurado, and M. Marcos (2008), A mesoscale index to describe the regional circulation around the Balearic Islands, J. Mar. Syst., 71, 413-420, doi:10.1016/j.jmarsys.2006.11.012.
Nencioli, F., C. Dong, T. Dickey, L. Washburn, and J. C. McWilliams (2010), A vector geometry-based eddy detection algorithm and its application to a high-resolution numerical model product and high-frequency radar surface velocities in the southern California bight, J. Atmos. Oceanic Technol., 27, 564-579, doi:10.1175/2009JTECHO725.1.

Pascual, A., B. Buongiorno Nardelli, G. Lanicol, M. Emelianov, and D. Gomis (2002), A case of an intense anticyclonic eddy in the Balearic Sea (western Mediterranean), J. Geophys. Res., 107(C11), 3183.

Pinot, J. M., J. L. López-Jurado, and M. Riera (2002), The canales experiment (1996-1998). interannual, seasonal, and mesoscale variability of the circulation in the Balearic Channels, Prog. Oceanogr., 55(3-4), $335-370$.

Pinot, J. M., J. Tintoré, and D. Gomis (1994), Quasi-synoptic mesoescale variability in the Balearic Sea, Deep Sea Res., Part I, 41(516), 897-914.

Rio, M.-H., P.-H. Poulain, A. Pascual, E. Mauri, G. Larnicol, and R. Santoleri (2007), A mean dynamic topography of the mediterranean sea computed from altimetric data, in-situ measurements and a general circulation model, J. Mar. Syst., 65, 484-508, doi:10.1016/j. jmarsys.2005.02.006.

Rubio, A., B. Barnier, G. Jordà, M. Espino, and P. Marsaleix (2009), Origin and dynamics of mesoscale eddies in the Catalan Sea (NW Mediterranean): Insight from a numerical model study, J. Geophys. Res., 114, C06009, doi:10.1029/2007JC004245.

Ruiz, S., A. Pascual, B. Garau, F. Yannice, A. Álvarez, and J. Tintoré (2009), Mesoscale dynamics of the Balearic Front, integrating glider, ship and satellite data, J. Mar. Syst. (Elsevier), 78, S3-S16, doi:10.1016/j. jmarsys.2009.01.007.

Thomson, R. E., E. E. Davis, M. Heesemann, and H. Villinger (2010), Observations of long-duration episodic bottom currents in the Middle America Trench: Evidence for tidally initiated turbidity flows, J. Geophys. Res., 115, C10020, doi:10.1029/2010JC006166.

Tintoré, J., D.-P. Wang, and P. E. La Violette (1990), Eddies and thermohaline intrusions of the shelf-slope front off Northeast Spain, J. Geophys. Res., 95, 1627-1633.

Volkov, D. L., G. Larnicol, and J. Dorandeu (2007), Improving the quality of satellite altimetry data over continental shelves, J. Geophys. Res., 112, C06020, doi:10.1029/2006JC003765. 